\title{
Definitive Radiotherapy in Locally Advanced Non-Small Cell Lung Cancer: Dose and Fractionation
}

\author{
Nergiz Dağoğlu ${ }^{1}$, Şule Karaman ${ }^{2}$, Alptekin Arifoğlu³ ${ }^{3}$ Seden Küçücük ${ }^{1}$, Ethem N. Oral ${ }^{1}$ \\ ${ }^{1}$ Department of Radiation Oncology, İstanbul University İstanbul Faculty of Medicine, İstanbul, Turkey \\ ${ }^{2}$ Department of Radiation Oncology, Liv Hospital, İstanbul, Turkey \\ ${ }^{3}$ Department of Radiation Oncology, Neolife Medical Center, İstanbul, Turkey
}

Definitive radiotherapy plays a major role in the treatment of locally advanced non-small cell lung cancer (LA NSCLC). After the impact of RT dose for lung cancer was established, a number of trials were structured with the aim of better local control and overall survival by either dose escalation or shortening the total treatment time through conventional/altered fractionation, even in combination with chemotherapy (CT) and other targeted agents. In spite of the increased number of these studies, the optimal dose or fraction- ation still remains to be determined. Another aspect questioned is the incorporation of these higher doses and shorter treatment times with chemotherapy or targeted agents. This review summarises the results of significant trials on dose and altered fractionation in the treatment of LA-NSCLC with an emphasis on possible future perspectives.

Key Words: Dose, fractionation, non-small cell lung cancer, radiotherapy
Lung cancer is the leading cause of cancer-related mortality for both men and women. Among all cases, non-small cell lung cancer (NSCLC) accounts for $70-80 \%$ and almost half of the cases are considered to be locally advanced (LA) or unresectable disease at first presentation (1). Until only a decade ago, conventional fractionated radiotherapy (RT) alone applied at a dose of $60 \mathrm{~Gy}$ in $2 \mathrm{~Gy}$ fractions over 6 weeks was accepted as the standard nonsurgical treatment for these patients. However, the results were discouraging as the median survival obtained was less than a year and the 2-year survival rate did not go above $15-20 \%$ (2).

After the impact of RT dose for lung cancer was established (3), a number of trials were structured in the quest for better local control and overall survival by either dose escalation or shortening the total treatment time through conventional/altered fractionation, even in combination with chemotherapy (CT) and other targeted agents.

This review summarises the results of significant trials on dose and altered fractionation in the treatment of LA-NSCLC with an emphasis on possible future perspectives. The included trials were evaluated under two main titles as "Dose and Dose Escalation" and "Treatment Duration and Altered Frac- tionation". It should be noted that there is not always a distinct differentiation among the trials as some of the studies address both aspects. In the case of overlap, trials were grouped according to the main hypothesis which they were designed to answer.

\section{DOSE AND DOSE ESCALATION}

Several studies have confirmed the relationship for dose and tumour response that led to an ameliorated local control and survival (Table 1).

The first trial that validated the advantage of dose escalation for LA-NSCLC was the Radiation Therapy Oncology Group (RTOG) 73-01 trial, where 376 patients were randomised into four arms (2). Three arms included standard fractionation with doses of 40, 50 and 60 Gy in 2 Gy fractions and the fourth arm included a split course RT that was applied in 4 Gy fraction size to a total dose of 40 Gy over 5 weeks with a 3 week interruption in the middle. The overall 3 year intrathoracic failure rate was $33 \%$ for patients treated in the $60 \mathrm{~Gy}$ arm; this was significantly lower when compared to the other arms, with re-

Address for Correspondence: Dr. Nergiz Dağoğlu, Department of Radiation Oncology, İstanbul University İstanbul Faculty of Medicine, İstanbul, Turkey Phone: +90 5323336383 e-mail: ranedag@yahoo.com

Received: 09.06.2014 Accepted: 09.10.2014 • DOI: 10.5152/balkanmedj.2014.14496

Available at www.balkanmedicaljournal.org 
TABLE 1. Dose escalation studies

\begin{tabular}{|c|c|c|c|c|c|c|c|}
\hline Study & $\mathrm{Pt} \#$ & RTdose/fr\# & & $\mathrm{CT}$ & & Findings & \\
\hline \multirow[t]{4}{*}{ RTOG 7301 (2) } & 376 & Arm1: & $40 \mathrm{~Gy} / 20 \mathrm{fr}$ & - & $3 y-L F$ & $\mathrm{p}=0.02$ & Established \\
\hline & & Arm2: & $50 \mathrm{~Gy} / 25 \mathrm{fr}$ & & & $42 \%$ & $60 \mathrm{~Gy}$ as \\
\hline & & Arm3: & $60 \mathrm{~Gy} / 30 \mathrm{fr}$ & & & $33 \%$ & standard dose \\
\hline & & Arm4: & 40 Gy split course & & & $44 \%$ & \\
\hline \multirow[t]{7}{*}{ RTOG 9311 (4) } & 177 & Group 1 (V20<25\%): & $70.9 \mathrm{~Gy} / 33 \mathrm{fr}$ & - & MTD for Group 1: & $83.8 \mathrm{~Gy}$ & \\
\hline & & & $77.4 \mathrm{~Gy} / 36 \mathrm{fr}$ & & & & \\
\hline & & & $83.8 \mathrm{~Gy} / 39 \mathrm{fr}$ & & & & \\
\hline & & & $90.3 \mathrm{~Gy} / 42 \mathrm{fr}$ & & & & \\
\hline & & Group $2(\mathrm{~V} 20=25-36 \%)$ & $70.9 \mathrm{~Gy} / 33 \mathrm{fr}$ & & MTD for Group 2: & 77 Gy & \\
\hline & & & $77.4 \mathrm{~Gy} / 36 \mathrm{fr}$ & & & & \\
\hline & & Group $1(\mathrm{~V} 20>37 \%)$ : & Closed early & & Poor accrual & & \\
\hline \multirow[t]{5}{*}{ MSKCC trial (5) } & 104 & Phase I & $70.2 \mathrm{~Gy} / 39 \mathrm{fr}$ & - & MTD: & $84 \mathrm{~Gy}$ & \\
\hline & & & $75.6 \mathrm{~Gy} / 42 \mathrm{fr}$ & & & & \\
\hline & & & $81 \mathrm{~Gy} / 45 \mathrm{fr}$ & & & & \\
\hline & & & $84 \mathrm{~Gy} / 42 \mathrm{fr}$ & & & & \\
\hline & & & $90 \mathrm{~Gy} / 45 \mathrm{fr}$ & & & & \\
\hline \multirow[t]{2}{*}{ RTOG 0117 (7) } & 8 & Phase I & $75.25 \mathrm{~Gy} / 35 \mathrm{fr}$ & Carboplatin/ Paclitaxel & High toxicity & & \\
\hline & 53 & Phase II & $74 \mathrm{~Gy} / 37 \mathrm{fr}$ & Carboplatin/ Paclitaxel & 1y OS: & $75.7 \%$ & \\
\hline \multirow[t]{3}{*}{ NCCTG N0028 (8) } & 15 & Phase I & $70 \mathrm{~Gy} / 35 \mathrm{fr}$ & Carboplatin/ Paclitaxel & MTD: & 74Gy + Carbopla & n/ Paclitaxel \\
\hline & & & $74 \mathrm{~Gy} / 37 \mathrm{fr}$ & Carboplatin/ Paclitaxel & & & \\
\hline & & & $78 \mathrm{~Gy} / 39 \mathrm{fr}$ & Carboplatin/ Paclitaxel & & & \\
\hline \multirow[t]{2}{*}{ CALGB 30105 (9) } & 43 & Arm A & $74 \mathrm{~Gy} / 37 \mathrm{fr}$ & Carboplatin/ Paclitaxel & 1y OS: & $66.7 \%$ & \\
\hline & 26 & Arm B & $74 \mathrm{~Gy} / 37 \mathrm{fr}$ & Carboplatin/gemcitabine & & $\begin{array}{l}50 \% \text { (Closed earl) } \\
\text { unaccepted toxici }\end{array}$ & $\begin{array}{l}\text { because of } \\
\text { y) }\end{array}$ \\
\hline
\end{tabular}

RTOG: Radiation Therapy Oncology Group; MSKCC: Memorial Sloan Kettering Cancer Center; NCCTG: The North Central Cancer Treatment Group; CALGB: The Cancer and Leukaemia Group B; Pt\#: number of patients; RT: radiotherapy; fr\#: fraction number; Gy: Gray; fr: fractions; CT: Chemotherapy; LF: local failure; MTD: maximum tolerated dose; OS: overall survival

sults of $42 \%, 44 \%$ and $52 \%$ for $50 \mathrm{~Gy}, 40$ Gy with split course, and 40 Gy with conventional schedule, respectively $(\mathrm{p}=0.02)$. Patients that achieved complete tumour response reported an increased survival as the 3 year survival was $23 \%$ for complete responders, $10 \%$ for partial responders, and $5 \%$ for patients with stable disease. The dose of $60 \mathrm{~Gy}$ was found to be superior to 40 or $50 \mathrm{~Gy}$ of irradiation with regard to tumour response, intrathoracic control and overall survival. This predominance demonstrated a correlation among tumour response, local control and survival and established the optimal dose for LA-NSCLC as 60 Gy in 30 fractions.

For approximately two decades, attempts to conduct trials that compare higher and lower doses of RT in LA NSCLC were prevented because of the toxicity risk. Three-dimensional conformal RT (3D-RT) provided the opportunity to increase tumour dose while minimising the dose to normal tissues such as the heart, oesophagus, and healthy lung. With this technical approach, multiple phase I dose escalation studies were formed to evaluate the benefit of doses higher than 60 Gy $(4,5)$.

The RTOG 9311 trial tested dose escalation using 3D-RT (4). This study stratified 177 stage I-III NSCLC patients at increasing dose levels based on the lung volume subjected to more than 20 Gy (V20 Gy). The preferred fraction size was 2.15 Gy. Group 1 comprised patients with V20 Gy less than $25 \%$ receiving 70.9 Gy, 77.4 Gy, 83.8 Gy or $90.3 \mathrm{~Gy}$, successively, and Group 2 included patients with a V20 Gy of 25-36\% in two dose levels: 70.9 Gy and 77.4 Gy. Group 3 was to recruit patients with a V20 Gy greater than $37 \%$, but this recruitment was adjourned due to poor accrual. For each study arm, overall survival and locoregional control rates in different dose groups were similar, but this comparison should still be addressed with caution because of the small sample size due to its MTD defining structure. Considering toxicity, the dosimetric factors were evaluated by multivariate analysis and the results verified that V20 Gy and the mean lung dose 
were significant risk factors for grade 3 or worse pulmonary adverse effects. This trial was interpreted as showing that 3DRT allowed dose escalation up to 83.8 Gy when V20 Gy could be kept at less than $25 \%$ and up to 77 Gy when V20 Gy could be kept between 25 and $36 \%$. Because of the two dose-related deaths reported, a dose of 90.3 Gy was considered unsafe.

Likewise, another study attempting dose escalation was executed in Memorial Sloan Kettering Cancer Center (MSKCC) (5). Although the daily fraction size was chosen to be 2.15 Gy in the RTOG 9311 trial, MSKCC used two different fraction sizes. For doses lower than $81 \mathrm{~Gy}$, it was preferred to be $1.8 \mathrm{~Gy}$, whereas for higher doses it was $2 \mathrm{~Gy}$. One hundred and four patients, $65 \%$ of whom had stage III disease, were enrolled in the MSKCC trial. Induction CT was applied in $16 \%$ of the patients. Ten patients were accrued at each dose level receiving the intended dose until a dose-limiting adverse effect was noted. Therefore, the total dose was increased from $70.2 \mathrm{~Gy}$, to 75.6 Gy, $81 \mathrm{~Gy}, 84 \mathrm{~Gy}$ and dose escalation had to be finalised at 90 Gy when unacceptable pulmonary toxicity occurred. Subsequently, with tolerable toxicity, ten more patients were enrolled for a dose of $84 \mathrm{~Gy}$. As a result, the accepted maximum tolerated dose (MTD) was stated to be 84 Gy. Among those patients who were deemed to be inoperable, the late pulmonary toxicity rate was $6 \%$. The 2 year survival among stage IIIA-B patients was $31 \%$, revealing a median survival of 15.6 months. In this group, those patients who received less than $80 \mathrm{~Gy}$ had an overall survival at 2 years of $23 \%$, while those who received more than 80 Gy had a rate of $52 \%$. The authors also reported the initiation of a follow-up study to compare $84 \mathrm{~Gy}$ with the historic standard treatment arm of $60 \mathrm{~Gy}$.

After the concurrent chemoradiotherapy (CRT) regimes became the standard of treatment (6), dose escalation studies were also modified in this setting. RTOG 0117 was designed in two phases: Phase I aimed to determine the MTD for conventional fractionated RT when applied concurrently with weekly carboplatin and paclitaxel, while the identified dose was to be tested for efficacy in phase II (7).

For the phase I part, total dose initially was identified as 75.25 Gy and fraction size as 2.15 Gy, but grade 3 toxicity developed in six out of the eight patients. After lowering the dose to $74 \mathrm{~Gy}$ and fraction size to $2 \mathrm{~Gy}$, only one patient among the seven had grade 3 toxicity. Depending on the results in phase I, 74 Gy in 2 Gy fractions was specified as the MTD and subsequently applied in 53 patients for the phase II trial. In the subgroup analysis for stage III disease, median progression free and overall survival times were 10.8 months and 21.6 months, respectively; these survival rates were among the best reported compared to earlier RTOG trials.

The North Central Cancer Treatment Group (NCCTG) also published the results for a phase I trial that escalated the dose using 3-DRT. As in the RTOG 0117 trial, NCCTG also administered carboplatin and paclitaxel concurrently with RT (8). Fifteen LA NSCLC patients entered into the trial. RT was composed of 70 Gy in 2 Gy fractions initially, and later, for each level, the dose was escalated by 4 Gy until a dose-limiting toxicity appeared. Unacceptable toxicity did not appear in any of the three patients prescribed with $70 \mathrm{~Gy}$; it was seen only in one of the six patients prescribed $74 \mathrm{~Gy}$, and in two of the four patients prescribed $78 \mathrm{~Gy}$. In a 28-month median follow-up, three deaths were observed. As a result, in both the NCCTG and RTOG 0117 trials, MTD was defined as 74 Gy and pulmonary adverse effects were considered the dose-limiting toxicity.

To define the optimal CT to use with $74 \mathrm{~Gy}$ as the prescribed dose, the Cancer and Leukaemia Group B (CALGB) organised the CALGB 30105 trial in a phase II setting (9). Sixty nine patients were enrolled in CALGB 30105 to either arm A, for treatment with induction carboplatin and paclitaxel followed by the identical regimen used weekly together with RT of 74 Gy, or in arm B, to be treated with induction carboplatin with gemcitabine, followed by concurrent gemcitabine and RT of 74 Gy. Arm A recruited 43 patients and arm B recruited 26. Owing to the high rate of pulmonary toxicity, arm B had to be terminated prematurely. The median survival time and 1-year survival rate were 24.3 months and $66.7 \%$ and 12.5 months and $50 \%$, respectively, for arms A and B. Recently, Salama et al. (10) reported the secondary analysis for the trial. Other than known risk factors such as V20 Gy and N3 nodal stage, concurrent gemcitabine was associated with a greater risk of toxicity in the $74 \mathrm{~Gy}$ arm in multivariate analysis, highlighting the importance of agent choice to be used concurrently with higher doses of RT.

In accordance with these results, Mehta et al. (11) retrospectively examined seven prospective RTOG trials including a total of 1356 patients for the association of dose and clinical outcome. This analysis revealed that studies with higher biologically effective doses (BEDs) were consistent with improved local control and overall survival. A 1 Gy increment in BED reduced the relative risk of death by approximately $4 \%$. Despite the limitations and potential biases related to its retrospective nature, the findings of this study supported the suggestion that dose intensity holds a critical place for NSCLC treatment.

On the basis of the complimentary data from these trials, RTOG, NCCTG and CALBG joined efforts to conduct RTOG 0617 as an intergroup trial. RTOG 0617 was designed as a four arm study. It was planned with the aim of comparing concurrent carboplatin plus paclitaxel with or without cetuximab together with either $60 \mathrm{~Gy}$ as a standard dose or 74 Gy as high dose. Both arms used 2 Gy once daily fractions; therefore, while increasing the dose, the $74 \mathrm{~Gy}$ arm also 
extended the treatment duration from 6 weeks to 7.5 weeks. The interim results (12) showed worse 1 year survival for high dose arms than the standard dose arms, with results of $70.4 \%$ versus $81 \%$. Although the reported toxicity did not reach a significant difference between the groups, 17 deaths were observed in the two 74 Gy arms but only seven in the two 60 Gy arms. The arms for the high dose were dismissed as a result of findings. Underreported severe toxicity of high radiation doses, especially given concurrently with carboplatin and paclitaxel, as well as prolonged total treatment time of 7.5 weeks, were considered the possible reasons for survival failure (13).

\section{TREATMENT DURATION AND ALTERED FRACTIONATION}

Non-small cell lung cancer has been established as a rapidly proliferating neoplasm (14). The objective of altered fractionation is to overcome this by changing the dose per fraction in order to increase the total dose or by reducing the total treatment time or combining both.

Altered fractionations studies for LA NSCLC are conducted with the aim of improving the therapeutic ratio through hyperfractionation, accelerated RT, hyperfractionated accelerated RT or hypofractionation (Table 2).

Hyperfractionated radiotherapy (HyperFRT) involves smaller doses per fraction than conventional RT, but it is administered multiple times daily. In contrast, a more conventional fraction size is used with accelerated RT (ART), in order to provide shorter total treatment time with the intention of targeting the repopulation of tumour cells. Hypofractionation (HypoFRT), on the other hand, includes fewer but larger doses per fraction delivered to increase total dose. Usually, ART is combined with either HypoFRT or HyperFRT.

TABLE 2. Total dose, treatment time and dose per fraction changes for each fractionation type in comparison with conventional fractionation

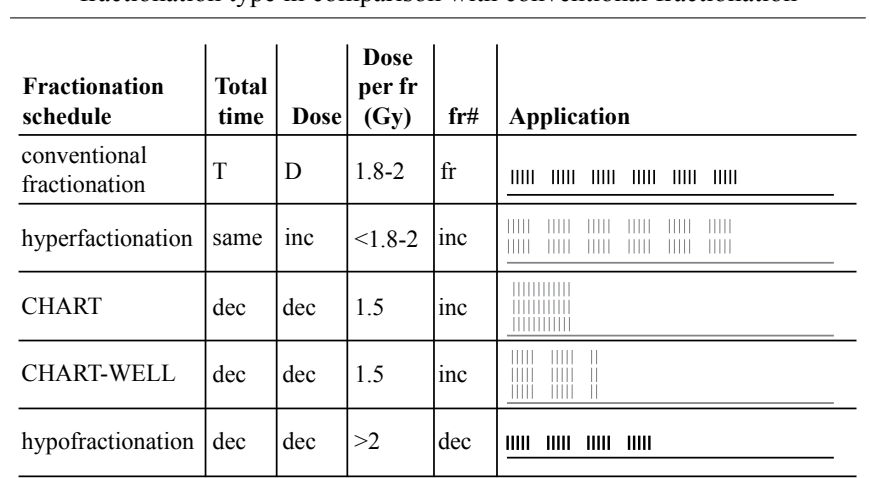

CHART: continuous hyperfractionated accelerated radiotherapy; CHART-WELL: continuous hyperfractionated accelerated radiotherapy-weekend less; fr: fraction; Gy: gray; fr\#: fraction number; T: treatment time; D: total dose; inc: increased; dec: decreased
A recent meta-analysis by Mauguen et al. (15) evaluated ten trials including 2,000 patients and concluded that modifying the radiotherapy schedule by HyperFRT, ART or both resulted in an increase of overall survival. Employing altered fractionation reduced the risk of death by $12 \%$ and enhanced the 3 - and 5-year survival rates, as an absolute overall survival increment was succeeded by $3.8 \%$ at 3 years and $2.5 \%$ at 5 years. On the other hand, altered fractionation increased oesophagitis risk from $9 \%$ to $19 \%(\mathrm{p}<0.001)$, and, as expected, the most accelerated regimes were associated with the most severe toxicity. However, at least $90 \%$ of patients completed the planned RT similarly to the control arms. In spite of the growing evidence for HyperFRT and ART, there have been only a few studies to address dose escalation or acceleration through HypoFRT.

\section{Hyperfractionation}

To evaluate the optimal dose for Hyper FRT, RTOG 8311 was designed as a phase II study (16). Randomisation was among doses of $60,64.8,69.6,74.4$ or 79.2 Gy administered in twice daily 1.2 Gy fractions with a minimum of four hour intervals in between. Three hundred and fifty of the 848 patients had favourable prognostic factors of a 70 or higher Karnofsky performance status or a less than 5\% weight loss. For this subgroup of patients, survival rates were higher with 69.6 Gy compared to the lower dose groups. However, dose escalation beyond 69.6 Gy did not show any survival benefit.

Taking into consideration the results of RTOG 8311, the 69.6 Gy arm was tested in RTOG 8808/Eastern Cooperative Oncology Group (ECOG) 4588 trial (6). Four hundred and fifty two patients were accrued in three arms. In two arms, treatment included only RT: one using conventional RT with 60 Gy given in 2 Gy fractions while the other arm was using HyperFRT with 69.6 Gy given twice daily in 1.2 Gy fractions. The third arm applied conventional RT with induction CT consisted of cisplatin and vinblastine administered for 5 consecutive weeks. In the preliminary analysis, the CRT arm demonstrated a 13.8 month median survival which was superior to both the 12.3 month median survival of HyperFRT arm and 11.4 month of the conventional fractionation arm. These results justified consideration of the CRT arm as the new standard. However, when 5 year survivals were announced, the distinct difference lessened as the CRT and HyperFRT arms showed survivals of $8 \%$ versus $6 \%$, respectively $(\mathrm{p}=0.04)(17)$.

Although the RTOG 8808/ECOG 4588 trial did not indicate any superiority for HyperFRT, it yielded the organisation of other trials $(18,19)$, which tested HyperFRT in combination with CT. The RTOG 9106 trial (18) demonstrated the results of using cisplatin and etoposide with $69.6 \mathrm{~Gy}$ arm. Since the patient characteristics were similar to those enrolled onto the 
RTOG 8808 trial, the results of RTOG 9106 were compared to the RT alone hyperfractionated arm of RTOG 8808 , and the combination of HyperFRT and CT showed promising results (18). Moreover, Jeremic et al. (19) published another randomised trial that used a lower dose $\mathrm{CT}$ regimen with carboplatin and etoposide each week given concurrently with HyperFRT administered as twice daily 1.2 Gy fractions to $64.8 \mathrm{~Gy}$; this significantly prolonged the duration for overall survival from 8 months to 18 months when compared with HyperFRT alone $(\mathrm{p}=0.0027)$.

One of the pivotal trials for the treatment of LANSCLC was the RTOG 9410 study (20). It was considered 'a milestone' in the management of LA NSCLC in terms of demonstrating the advantage of concurrent over sequential CT (21). This three arm study randomised 610 patients to sequential CRT with cisplatin/vinblastine followed by RT delivered in 30 fractions of 2 Gy over 6 weeks to a total dose of 60 Gy beginning on day 50 (arm 1); or concurrent CRT with combination cisplatin/ vinblastine and the same RT beginning on day 1 (arm 2); or concurrent CRT using combination cisplatin/etoposide with HyperFRT beginning on day 1 delivered in 1.2 Gy fraction sizes twice daily, over six weeks to 69.6 Gy (arm 3). Benefit for survival in the study was higher with the concurrent regimen consisting of once-daily radiotherapy (arm 2) when compared to the concurrent regimen using HyperFRT (arm 3). Five year survivals were $10 \%, 16 \%$ and $13 \%$ for arms $1-3$, respectively $(\mathrm{p}=0.046)$. Results were viewed as disappointing for arm 3, which was attributed to grade 3 toxicity noted in $45 \%$ of patients and to the delivery of a hyperfractionation regime over a conventional overall treatment time (21). Table 3 summarises the HyperFRT trials.

\section{Hyperfractionated accelerated RT}

Evidence suggests that in NSCLC, reducing the overall treatment time is as crucial as the dose escalation in order to overcome the impact of rapid repopulation of this tumour (21). In response to this, a randomised trial investigating the continuous hyperfractionated accelerated radiotherapy (CHART) schedule was organised with contribution from multiple centres in the UK $(22,23)$. The CHART schedule was consisted of $1.5 \mathrm{~Gy}$ fractions for three times a day applied without break through 12 days consecutively to $54 \mathrm{~Gy}$ in total. Five hundred and sixty three patients were randomised at a 3:2 ratio to either the CHART schedule or conventional RT applied as $60 \mathrm{~Gy}$ in

TABLE 3. Studies using hyperfractionation

\begin{tabular}{|c|c|c|c|c|c|c|}
\hline Study & $\mathrm{Pt} \#$ & RTdose/fr\# & & $\mathrm{CT}$ & Fin & \\
\hline \multirow[t]{5}{*}{ RTOG 8311} & \multirow[t]{5}{*}{848} & \multirow[t]{5}{*}{ Phase II } & $60 \mathrm{~Gy} / 1.2 \mathrm{~Gy}$ bid & - & \multirow{5}{*}{$\begin{array}{l}\text { For } 350 \text { patients with } \\
\text { favourable prognostic } \\
\text { factors }\end{array}$} & Survival rates were higher \\
\hline & & & $64.8 \mathrm{~Gy} / 1.2 \mathrm{~Gy}$ bid & & & with 69.6 Gy than with the \\
\hline & & & $69.6 \mathrm{~Gy} / 1.2 \mathrm{~Gy}$ bid & & & lower doses. There were no \\
\hline & & & $74.4 \mathrm{~Gy} / 1.2 \mathrm{~Gy}$ bid & & & differences in survival rates \\
\hline & & & $79.2 \mathrm{~Gy} / 1.2 \mathrm{~Gy}$ bid & & & among the three highest doses \\
\hline \multirow[t]{6}{*}{ RTOG 8808/ ECOG 4588} & \multirow[t]{6}{*}{452} & \multirow[t]{2}{*}{ Arm 1: } & \multirow[t]{2}{*}{$60 \mathrm{~Gy} / 2 \mathrm{~Gy}$} & \multirow[t]{2}{*}{-} & $1 \mathrm{y} O S$ & $46 \%$ \\
\hline & & & & & $5 y$ OS & $5 \%$ \\
\hline & & \multirow[t]{2}{*}{ Arm 2: } & \multirow[t]{2}{*}{$60 \mathrm{~Gy} / 2 \mathrm{~Gy}$} & \multirow[t]{2}{*}{ (ind)CDDP/Vinblastine } & $1 \mathrm{yOS}$ & $60 \%$ \\
\hline & & & & & $5 \mathrm{y}$ OS & $8 \%$ \\
\hline & & \multirow[t]{2}{*}{ Arm 3: } & $69.6 \mathrm{~Gy} / 1.2 \mathrm{~Gy}$ & \multirow[t]{2}{*}{-} & $1 \mathrm{y} O S$ & $51 \%$ \\
\hline & & & bid & & $5 y$ OS & $6 \%$ \\
\hline \multirow[t]{2}{*}{ RTOG 9106} & \multirow[t]{2}{*}{104} & \multirow[t]{2}{*}{ Phase II } & $69.6 \mathrm{~Gy} / 1.2 \mathrm{~Gy}$ & \multirow[t]{2}{*}{ CDDP/Etoposide } & $1 \mathrm{y} O S$ & $67 \%$ \\
\hline & & & bid & & $5 \mathrm{y}$ OS & $35 \%$ \\
\hline \multirow[t]{5}{*}{ Jeremic et al. (19) } & \multirow[t]{5}{*}{169} & Arm 1: & $64.8 \mathrm{~Gy} / 1.2 \mathrm{~Gy}$ bid & - & \multirow[t]{5}{*}{ 3y OS: } & $6 \%$ \\
\hline & & Arm 2: & $64.8 \mathrm{~Gy} / 1.2 \mathrm{~Gy}$ & Carboplatin (100mg)/ & & \\
\hline & & & bid & Etoposide & & $23 \%$ \\
\hline & & \multirow[t]{2}{*}{ Arm 3: } & $64.8 \mathrm{~Gy} / 1.2 \mathrm{~Gy}$ & Carboplatin (200mg)/ & & \\
\hline & & & bid & Paclitaxel & & $16 \%$ \\
\hline \multirow[t]{3}{*}{ RTOG 9410} & \multirow[t]{3}{*}{610} & Arm 1: & $60 \mathrm{~Gy} / 2 \mathrm{~Gy}$ & - & \multirow[t]{3}{*}{ 5y OS: } & $10 \%$ \\
\hline & & Arm 2: & $69.6 \mathrm{~Gy} / 1.2 \mathrm{~Gy}$ bid & CDDP/Vinblastine & & $16 \%$ \\
\hline & & Arm 3: & $69.6 \mathrm{~Gy} / 1.2 \mathrm{~Gy}$ bid & CDDP/Etoposide & & $13 \%$ \\
\hline
\end{tabular}

RTOG: Radiation Therapy Oncology Group; ECOG: Eastern Cooperative Oncology Group; Pt\#: number of patients; RT: radiotherapy; fr\#: fraction number; Gy: Gray; bid: twice daily; CT: chemotherapy; ind: induction; OS: overall survival 
2 Gy fractions. The results demonstrated the superiority of the CHART schedule with overall survival rates of $30 \%$ versus $21 \%$ at 2 years and $20 \%$ versus $13 \%$ at 3 years for CHART and conventional RT, respectively. These results corresponded to a $22 \%$ decrease for relative risk of death at 3 years. In subgroup analysis, CHART showed an even greater improvement for squamous cell carcinomas, with an overall survival at 3 years of $21 \%$ compared with $11 \%$ for the conventional regime.

On the basis of these results, this schema was modified to have a more practical schedule in which treatment was not applied on weekends and therefore named "CHART-WEL", standing for CHART "weekend less" (24). A phase III trial was conducted to test the delivery of 60 Gy over a 2.5 week period using this schema, which includes the 1.5 Gy for a three times daily regime, as in CHART excluding therapy during the weekend. Four hundred and six patients were randomised either to the CHART-WEL schedule or to conventionally fractionated RT delivered as 66 Gy in 33 fractions over a 6.5 week period. The results were similar between the two arms for overall and progression-free survival. It should be noted that as a $10 \%$ lower total dose was given in the CHARTWEL arm, this similarity actually reinforced the importance of time for NSCLC as the lower total dose could be compensated by the shorter overall treatment time.

The CHARTWEL trial might also be viewed as a possible answer to some of the criticisms raised after the CHART study, other than the logistic problem of the treatment schedule. In the CHART study, stage I-II disease comprised $36 \%$ of the study population, who would be considered for a surgical approach or for stereotactic body RT; most of the patients (82\%) had squamous cell carcinoma. Moreover, the control arm would not be considered a current standard of care as CT was not delivered with RT, either sequentially or concurrently (25). On the contrary, in the CHARTWEL trial, most patients were stage III and only $57 \%$ had squamous cell carcinoma (24). However, only $26 \%$ of patients got CT.

Despite the limitations of the CHART or CHARTWEL studies, the high efficacy of these hyperfractionated accelerated RT (HART) schedules provided a basis for further trials on treatment intensification for locally advanced NSCLC in combination with CT $(26,27)$. The INCH trial tested this combined modality approach (26). In this study, 46 patients were randomised to CHART either alone or in combination with induction CT for three cycles; however, as a result of poor accrual, the study closed early. The median survival of 17 months with CHART alone was similar to that observed in previous studies. On the other hand, the median survival of 25 months was achieved for the $\mathrm{CT}$ arm, but statistical significance was not obtained. Nevertheless, the INCH trial confirmed the feasibility of CHART in combination with CT, with $87 \%$ of patients completing the intentional treatment. The ECOG 2597 (27) tested a modified CHART schedule with weekends off. After two cycles of induction CT, patients were randomised between hyperfractionated accelerated RT delivered three times daily in 1.5 Gy fractions to 57.6 Gy and conventional RT in 32 daily fractions to 64 Gy. This trial was also closed earlier than expected, after 141 patients were recruited, because of slow accrual. Although a statistical significance was not maintained at the final analysis, a 15\% improvement in favour of the HART arm in 2 and 3 year survival was detected.

The evolving evidence from phase II trials also pointed to the feasibility of concurrent CT with HART (28-30). This approach was studied in a three arm multi-centric Swedish trial (31). One hundred and fifty two patients were randomised after 2 cycles of induction CT of paclitaxel and carboplatin. In arm A, one more cycle of the same CT was given with the initiation of HART applied twice daily as a 1.7 Gy fraction to 64.6 Gy. The other two arms used conventionally fractionated RT delivered in daily fractions of 2 Gy to 60 Gy in total, but in arm B, RT was applied with concomitant daily paclitaxel whereas in arm $\mathrm{C}$, concomitant paclitaxel was administered weekly. The 3 year overall survival was 33\% for arm A, 36\% for arm B and $21 \%$ for arm C. Treatment outcomes were quite equal in respect to both survival and toxicity. Despite the promising results, studies reported were small and heterogeneous, still yielding the need to define the convenience and adequacy of HART when used concurrently with $\mathrm{CT}$ in a further phase III study.

\section{Hypofractionation}

There are only a few studies that have been designed to test dose escalation or acceleration through hypofractionation. Slawson et al. assessed HypoFRT in a randomised trial (32); to date, this is the only randomised trial reported in this setting. In this trial, 63 patients received conventional RT of 60 Gy in 2 Gy fractions and 57 patients received HypoFRT of 60 Gy in 5 Gy fractions. While the conventional RT arm was delivered in 5 fractions per week for 6 weeks, the HypoFRT arm involved only 1 fraction per week for 12 weeks. Although no data were provided to assess whether the results were statistically significant or not, the HypoFRT arm revealed better local control and survival rates. Complete tumour responses were similar in both arms, with the HypoFRT arm demonstrating a numerical advantage ( $26 \%$ versus $17 \%$ ), and the 2 -year survival rate for HypoFRT was $29 \%$ compared with $23 \%$ for conventional RT. Seventy percent of HypoFRT patients did not experience any oesopihagitis compared with $30 \%$ in the conventional RT arm.

More recent trials for HypoFRT are designed as phase I/II. One of them, reported from the Netherlands Cancer Institu- 
te, aimed to find the MTD to be delivered (33). A total of 88 patients, $50 \%$ of whom had LA disease, were included. The total treatment time was not to extend beyond 6 weeks, with a fraction size of $2.25 \mathrm{~Gy}$; when the total dose was to be increased, the fractions were to be applied twice daily. Patients were evaluated in five groups, based on mean lung doses, and the dose was escalated unless a dose-limiting toxicity was detected. Higher doses were significantly associated with increased progression-free interval $(\mathrm{p}=0.02)$ for the entire study population. However, the overall survival increment was only noted in the lower risk groups $(\mathrm{p}=0.05)$.

Another phase I/II study was conducted in Brussels University Hospital (34) to determine the MTD, but this escalated not only the total dose but also the fraction size concurrently with CT. Fraction dose was increased by $6 \%$ starting at 2 Gy, with 2.48 Gy being the maximum. Thirty four patients had dose escalation for a total of 30 fractions, each in combination with docetaxel and cisplatin. There were no differences noted in means of acute toxicity. However, because the late lung toxicity increased with the 2.36 Gy fraction size, the MTD per fraction was defined as 2.24 Gy per fraction. The authors also announced the initiation of a phase II study to answer questions regarding effectiveness and tolerability with this schedule.

\section{FUTURE DIRECTIONS}

New technical advances in the application of RT enhanced the ability of targeted treatment and sparing of normal tissues, making high BED studies possible. In particular, the surprising results of the RTOG 0617 trial (12) drove attention to the importance of adverse effects, once again emphasising that future research should focus on quality of life as one of the factors directly related to survival and local control.

The interest in altered fractionation schedules in RT for LANSCLC is increasing, especially on hyperfractionated and accelerated schedules. On the other hand, HypoFRT is still approached with doubt. Data from HypoFRT studies were gathered with very heterogeneous approaches for total dose or fraction size over different time periods requiring the necessity for further research in phase II and III settings. Future directions for the alternative fractionation in management of this disease will be defined with studies that manage the incorporation of CT and targeted agents.

Peer-review: Externally peer-reviewed.

Author contributions: Concept - E.N.O., N.D.; Design - E.N.O., N.D.; Supervision - E.N.O., S.K.; Resource - N.D., Ş.K., A.A.; Materials - N.D., Ş.K., A.A.; Data Collection\&/or Processing - N.D., S..K., A.A.; Analysis\&/or
Interretation - E.N.O., N.D.; Literature Search - N.D., Ş.K., A.A.; Writing E.N.O., N.D., S.K.; Critical Reviews - E.N.O., N.D., S.K.

Conflict of Interest: No conflict of interest was declared by the authors.

Financial Disclosure: The authors declared that this review has received no financial support.

\section{REFERENCES}

1. Siegel R, Naishadham D, Jemal A. Cancer statistics, 2012. Cancer $J$ Clin 2012;62:10-29. [CrossRef]

2. Perez CA, Stanley K, Rubin P, Kramer S, Brady L, Perez-Tamayo R, et al. A prospective randomize study of various irradiation doses and fractionation schedules in the treatment of inoperable non-oat-cell carcinoma of the lung. Cancer 1980;45:2744-53. [CrossRef]

3. Martel MK, Ten Haken RK, Hazuka MB, Kessler ML, Strawderman M, Turrisi AT, et al. Estimation of tumor control probability model parameters from 3-D dose distributions of non-small cell lung cancer patients. Lung Cancer 1999;24: 31-7. [CrossRef]

4. Bradley J, Graham MV, Winter K. Toxicity and outcome results of RTOG 9311: A phase I-II dose escalation study using three-dimensional conformal radiotherapy in patients with inoperable non-small-cell lung carcinoma. Int J Radiat Oncol Biol Phys 2005;61:318-28. [CrossRef]

5. Rosenzweig KE, Fox JL, Yorke E. Results of a phase I dose-escalation study using three-dimensional conformal radiotherapy in the treatment of inoperable nonsmall cell lung carcinoma. Cancer 2005;103: 2118-27. [CrossRef]

6. Sause WT, Scott C, Taylor S, Johnson D, Livingston R, Komaki R, et al. Radiation Therapy Oncology Group (RTOG) 88-08 and Eastern Cooperative Oncology Group (ECOG) 4588: Preliminary results of a phase III trial in regionally advanced unresectable non-small-cell lung cancer. $J$ Natl Cancer Inst 1995;87:198-205. [CrossRef]

7. Bradley JD, Moughan J, Graham MV, Byhardt R, Govindan R, Fowler $\mathrm{J}$, et al. A Phase I/II radiation dose escalation study with concurrent chemotherapy for patients with inoperable stages I to III non-small-cell lung cancer: Phase I results of RTOG 0117. Int J Radiat Oncol Biol Phys 2010;77:367-72. [CrossRef]

8. Socinski MA, Rosenman JG, Halle J, Schell MJ, Lin Y, Russo S, et al. Dose-escalating conformal thoracic radiation therapy with induction and concurrent carboplatin/paclitaxel in unresectable stage IIIa/b nonsmall cell lung carcinoma: a modified phase I/II trial. Cancer 2001;92:1213-23. [CrossRef]

9. Socinski MA, Blackstock AW, Bogart JA, Wang X, Munley M, Rosenman J, et al. Randomized phase II trial of induction chemotherapy followed by concurrent chemotherapy and dose escalated thoracic conformal radiotherapy (74 Gy) in stage III non-small-cell lung cancer: CALGB 30105. J Clin Oncol 2008;26:2457-63. [CrossRef]

10. Salama JK, Stinchcombe TE, Gu L et al. Pulmonary toxicity in stage III non-small cell lung cancer patients treated with high-dose (74 Gy) 3-dimensional conformal thoracic radiotherapy and concurrent chemotherapy following induction chemotherapy: a secondary analysis of Cancer and Leukemia Group B (CALGB) trial 30105. Int J Radiat Oncol Biol Phys 2011;81:269-274. [CrossRef]

11. Machtay M, Bae K, Movsas B, Paulus R, Gore EM, Komaki R, et al. Higher biologically effective dose of radiotherapy is associated with improved outcomes for locallyadvanced non-small cell lung carcinoma treated with chemoradiation: an analysis of the Radiation Therapy Oncology Group. Int J Radiation Oncology Biol Phys 2012; 82: 425-34. [CrossRef] 12. Bradley JD, Paulus R, Komaki R, Masters G, Forster K, Schild SE, et al. A randomized phase III comparison of standard-dose ( $60 \mathrm{~Gy})$ versus high- 
dose (74 Gy) conformal chemoradiotherapy with or without cetuximab for stage IIIa/IIlb non-small cell lung cancer: preliminary findings on radiation dose in RTOG 0617. Presented at: 53rd Annual Meeting of the American Society of Radiation Oncology. Miami, FL, USA, 2-6 October 2011.

13. Chang JY, De Ruysscher D. Individualized hypo/hyperfractionated radiotherapy for non-small cell lung cancer. $J$ Thorac Dis 2014;6:285-6.

14. Kerr KM, Lamb D. Actual growth rate and tumour cell proliferation in human pulmonary neoplasms. Br J Cancer 1984;50:343-9. [CrossRef]

15. Mauguen A1, Le Péchoux C, Saunders MI, Schild SE, Turrisi AT, Baumann $\mathrm{M}$, et al. Hyperfractionated or accelerated radiotherapy in lung cancer: An individual patient data meta-analysis. J Clin Oncol 2012;30:2788-97. [CrossRef]

16. Cox JD, Azarnia N, Byhardt RW, Shin KH, Emami B, Pajak TF. A randomized phase I/II trial of hyperfractionated radiation therapy with total doses of 60.0 Gy to 79.2 Gy: possible survival benefit with $\geq 69.6$ Gy in favorable patients with Radiation Therapy Oncology Group stage III non-smallcell lung carcinoma: report of Radiation Therapy Oncology Group 83-11. J Clin Oncol 1990;8:1543-55.

17. Sause W, Kolesar P, Taylor S IV, Johnson D, Livingston R, Komaki R, et al. Final results of Phase III trial in regionally advanced unresectable non-small cell lung cancer: Radiation Therapy Oncology Group, Eastern Cooperative Oncology Group, and Southwest Oncology Group. Chest 2000;117:358-64. [CrossRef]

18. Lee JS, Scott C, Komaki R et al. Concurrent chemo-radiotherapy with oral VP-16 and cisplatin for locally advanced inoperable non-small cell lung cancer: RTOG protocol 91-06. J Clin Oncol 1996;14:1055-64.

19. Jeremic B, Shibamoto Y, Acimovic L, Djuric L. Randomized trial of hyperfractionated radiation therapy with or without concurrent chemotherapy for stage III non-small-cell lung cancer. J Clin Oncol 1995; 13:452-8.

20. Curran WJ Jr, Paulus R, Langer CJ, Komaki R, Lee JS, Hauser S, et al. Sequential vs. concurrent chemoradiation for stage III non-small cell lung cancer: randomized phase III trial RTOG 9410. J Natl Cancer Inst 2011;103:1452-60. [CrossRef]

21. Fournel P. RTOG 94-10: Keenly Awaited Results Validating the Best Therapeutic Strategy for Locally Advanced Non-Small Cell Lung Cancer. J Natl Cancer Inst 2011;103:1425-7. [CrossRef]

22. Saunders M, Dische S, Barrett A, Harvey A, Gibson D, Parmar M. Continuous hyperfractionated accelerated radiotherapy (CHART) versus conventional radiotherapy in non-small-cell lung cancer: a randomised multicentre trial. CHART Steering Committee. Lancet 1997;350:161-5. [CrossRef]

23. Saunders M, Dische S, Barrett A, Harvey A, Griffiths G, Palmar M. Continuous, hyperfractionated, accelerated radiotherapy (CHART) versus conventional radiotherapy in non-small cell lung cancer: mature data from the randomised multicentre trial. CHART Steering committee. $R a$ diother Oncol 1999;52:137-48. [CrossRef]
24. Baumann M, Herrmann T, Koch R, Matthiessen W, Appold S, Wahlers $\mathrm{B}$, et al. Final results of the randomized phase III CHARTWEL-trial (ARO 97-1) comparing hyperfractionated-accelerated versus conventionally fractionated radiotherapy in non-small cell lung cancer (NSCLC). Radiother Oncol 2011;100:76-85. [CrossRef]

25. Vokes EE. CHART for non-small-cell lung cancer-promises and limitations. Lancet 1997;350:156-7. [CrossRef]

26. Hatton M, Nankivell M, Lyn E, Falk S, Pugh C, Navani N, et al. Induction chemotherapy and continuous hyper-fractionated accelerated radiotherapy (CHART) for patients with locally advanced inoperable nonsmall cell lung cancer: the MRC INCH randomised trial. Int $J$ Radiat Oncol Biol Phys 2011; 81: 712-8. [CrossRef]

27. Belani CP, Wang W, Johnson DH, Wagner H, Schiller J, Veeder M, et al. Phase III study of the Eastern Cooperative Oncology Group (ECOG 2597): induction chemotherapy followed by either standard thoracic radiotherapy or hyperfractionated accelerated radiotherapy for patients with unresectable stage IIIa and b non-small-cell lung cancer. J Clin Oncol 2005;23:3760-7. [CrossRef]

28. Oral EN, Bavbek S, Kizir A, Tenececi N, Yöney A, Kaytan E, et al. Preliminary analysis of a phase II study of Paclitaxel and continuous hyperfractionated accelerated radiotherapy in locally advanced nonsmall cell lung cancer. Lung Cancer 1999;25:191-8. [CrossRef]

29. Oral EN. Long term results of CHART and weekly Paclitaxel in locally advanced non-small cell lung cancer. Lung Cancer 2005;49:421-2. [CrossRef]

30. Pöttgen C, Eberhardt W, Bildat S, Stüben G, Stamatis G, Hillejan L, et al. Induction chemotherapy followed by concurrent chemotherapy and definitive high dose radiotehrapy for patients with locally advanced non small cell lung cancer (stages IIIa/IIIb): a pilot phase I/II trial. Ann Oncol 2002;13:403-11. [CrossRef]

31. Nyman J, Friesland S, Hallqvist A, Seke M, Bergström S, Thaning L, et al. How to improve loco-regional control in stages IIIa-b NSCLC? Results of a three-armed randomized trial from the Swedish Lung Cancer Study Group. Lung Cancer 2009;65:62-7. [CrossRef]

32. Slawson RG, Salazar OM, Poussin-Rosillon H, Amin PP, Strohl R, Sewchand W. Once a week versus conventional daily radiation treatment for lung cancer: Final report. Int J Radiat Oncol Biol Phys 1988;15:61-8. [CrossRef]

33. Belderbos JS, Heemsbergen WD, De Jaeger K, Baas P, Lebesque JV. Final results of a phase I/II dose escalation trial in non-small cell lung cancer using three-dimensional conformal radiotherapy. Int $J$ Radiat Oncol Biol Phys 2006;66:126-34. [CrossRef]

34. Bral S, Duchateau M, Versmessen H, Verdries D, Engels B, De Ridder M, et al. Toxicity report of a phase I-II dose escalation study in patients with inoperable, locally advanced non small-cell lung cancer with helical tomotherapy and concurrent chemotherapy. Cancer 2010;116: $241-50$. 